\title{
Publisher's Note: Probing the Scale Invariance of the Inflationary Power Spectrum in Expanding Quasi-Two-Dimensional Dipolar Condensates [Phys. Rev. Lett. 118, 130404 (2017)]
}

Seok-Yeong Chä and Uwe R. Fischer

(Received 18 April 2017; published 26 April 2017)

DOI: 10.1103/PhysRevLett.118.179901

This Letter was published online on 30 March 2017 with an error on page 4. On page 4, the second line below Eq. (16) should read as "Setting $\kappa_{0}=50, \ldots$. " The Letter has been corrected as of 18 April 2017. The text is incorrect in the printed version of the journal. 